\title{
COVID-19 y manifestaciones cutáneas asociadas a trombosis ylo fenómenos microangiopáticos
}

\author{
COVID-19 and skin manifestations associated with \\ thrombosis and/or microangiopathic phenomena \\ Eduardo David Poletti Vázquez,* María Graciela Guzmán Perera ${ }^{\ddagger}$ \\ Citar como: Poletti VED, Guzmán PMG. COVID-19 y manifestaciones cutáneas asociadas a trombosis y/o fenómenos \\ microangiopáticos. Acta Med Grupo Angeles. 2021; 19 (s1): s21-s26. https://dx.doi.org/10.35366/101024
}

\section{Resumen}

La enfermedad por el virus SARS-CoV-2 produce hipoxemia silenciosa progresiva. El detrimento causado por el germen per se y el mediado por la "tormenta inmunológica" por células inflamatorias y citoquinas causan una severa destrucción de la estructura de los alveolos pulmonares, además de efectos trombóticos e inflamatorios, que aparecen por daño citotóxico (vasculitis) mediado por depósitos de complemento activado por la vía alterna a nivel de los pequeños vasos de toda la economía. Esto provoca una hipoxia grave de los tejidos, sobre todo de las zonas acrales. Las manifestaciones cutáneas varían desde lesiones purpúricas, púrpura retiforme, livedo racemosa, cianosis y necrosis (gangrena). Estas manifestaciones son marcadores de la severidad de la enfermedad y ensombrecen el pronóstico.

Palabras clave: Hipoxia, trombosis, vasculitis, púrpura, cianosis, necrosis.

Para muchos, en lugar de buscar una "causa de la muerte" cuando fallecen, deberíamos buscar una "causa de la vida" cuando aún siguen por aquí. Anónimo

\section{INTRODUCCIÓN}

En el curso del 2020 se ha aprendido que el SARS-CoV-2 es un beta-coronavirus que posee alta capacidad de

\section{Abstract}

The SARS-CoV-2 virus disease produces progressive silent hypoxemia. The damage caused by the germ per se, and that mediated by the "immune storm" by inflammatory cells and cytokines, provokes severe devastation of the structure of the pulmonary alveoli, in addition to thrombotic and inflammatory effects, which appear due to cytotoxic and complement activation (vasculitis) and deposition, at the level of the small vessels of the entire economy. This causes severe tissue hypoxia, especially in the acral areas. Cutaneous manifestations range from purpuric lesions, purpura retiform, livedo racemose, cyanosis, and necrosis (gangrene). These manifestations are markers of the severity of the disease and darken the prognosis.

Keywords: Hypoxia, thrombosis, vasculitis, purpura, cyanosis, necrosis.

mantenerse disperso (como aerosol en el aire por más de tres horas), sobrevive 72 horas en diversas superficies y tiene un periodo de incubación inferior a dos semanas, logrando una pronta carga viral alta en aparato respiratorio. También, en función del catastrófico número de fallecidos que ha provocado, queda claro que una mayor oxidación celular paralela al envejecimiento y la coexistencia con enfermedades como la diabetes mellitus, explica por qué los gerontes y las personas con enfermedades crónicas se

\footnotetext{
* Internista Dermatólogo en ejercicio privado en Aguascalientes, Ags. Profesor de la Facultad de Medicina de la Universidad Autónoma de Aguascalientes y Facultad de Medicina de la Universidad Cuauhtémoc, Expresidente de la Sociedad Mexicana de Cirugía Dermatológica. Miembro del Colmexiderma. México.

₹ Dermatóloga del Hospital Ángeles Pedregal. Expresidenta de la Academia Mexicana de Dermatología, Fundación Mexicana para la Dermatología y del Colmexiderma. México.
}

Correspondencia:

Eduardo David Poletti Vázquez

Correo electrónico: drpoletti@dermanorte.com.mx

www.medigraphic.com/actamedica

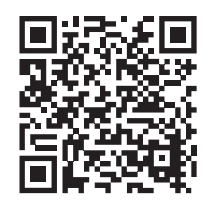


infectan más a menudo y más gravemente. ¿Se tendrá que usar mascarilla toda la vida?

En el presente artículo se pretende describir el daño vascular producido por el virus SARS-CoV-2, el papel de los efectos trombóticos y la tormenta inmunológica a nivel de la piel, y sus consecuencias.

\section{FISIOPATOLOGÍA DEL SARS-CoV-2 Y SUS EFECTOS EN LOS VASOS CUTÁNEOS}

Dentro de una célula anfitriona, el SARS-CoV-2 secuestra la maquinaria metabólica de la célula para replicarse y propagarse. Sus picos de proteína viral se adhieren a un receptor de proteína en la superficie de la célula anfitriona llamado ACE2, fusionando las membranas alrededor de la célula y el virus. Este proceso permite que ese germen entre en la célula y coopte su maquinaria de creación de proteínas, para hacer nuevas copias de sí mismo. Los estudios iniciales para la tipificación del nuevo coronavirus identificaron al receptor de superficie celular de la enzima convertidora de angiotensina tipo dos (ACE2), como el receptor clave en la patogénesis de la infección. Otras familias de coronavirus utilizan el receptor de la dipeptidilpeptidasa cuatro (DPP4). El receptor ACE2 se encuentra en la superficie de células epiteliales pulmonares, en los enterocitos del intestino delgado, en las células endoteliales de venas y arterias y en las células del músculo liso arterial de múltiples órganos, entre ellos el sistema tegumentario. ${ }^{1}$

La replicación viral dentro de las células causa daño celular directo, con liberación de alarminas proinflamatorias (efecto viral directo); sumado a esto, las partículas virales pueden crear respuestas inmunes innatas, que incluyen la activación de macrófagos alveolares y de la cascada del complemento a través de la vía de la lectina. ${ }^{1}$ Desde el momento en que comenzaron a reportarse enfermos con neumonía crítica por SARS-CoV-2, con fenómenos isquémicos acrales, como acrocianosis, púrpura retiforme y gangrena, se planteó la necesidad del uso de terapia anticoagulante ya que, a la par, se evidenciaron alteraciones en el dímero D, en el fibrinógeno y en los productos de éste. Actualmente, el manejo más optimizador en pacientes moderada a gravemente afectados, es usando dexametasona y enoxiparina. ${ }^{2}$ La fisiopatología subyacente a este hallazgo clínico no está clara, pero podría estar relacionada tanto con los efectos citotóxicos directos del virus como con la inflamación del huésped y las anomalías de la coagulación.

Fue precisándose que la tasa de mortalidad sería mayor al $70 \%$. El estado hipercoagulable per se en los enfermos con infección por SARS-CoV-2, es uno de los sucesos más graves con altas repercusiones en el sistema tegumentario. Continúan realizándose esfuerzos inauditos a diario para comprenderlos mejor, diagnosticarlos más precozmente y advertir las implicaciones ulteriores a nivel sistémico. ${ }^{3} \mathrm{El}$ contagio del síndrome respiratorio agudo grave por dicho virus se asocia con desórdenes trombóticos arteriales y venosos. En diversos registros, se han plasmado complicaciones trombóticas en que van del 3\% de enfermos hospitalizados no críticos hasta el 35\% de los hospitalizados en estado crítico. Se desconoce el riesgo de tromboembolismo en el contagio por SARS-CoV-2 en enfermos no hospitalizados. Los trastornos trombóticos incluyen infarto de miocardio, accidente cerebrovascular isquémico y tromboembolismo venoso, con más frecuencia. Los hallazgos de microtrombos en múltiples sistemas de órganos, incluidos los pulmones, el corazón y los riñones, sugieren que la trombosis puede contribuir a la disfunción de órganos multisistémicos en pacientes graves de COVID-19. Los conocedores del tema se han esforzado en estructurar un "algoritmo mundial" para el enfoque diagnóstico, el manejo clínico y el tratamiento. Es un área de investigación dinámica, y se esperan hallazgos en curso a medida que la pandemia continúe. ${ }^{4}$ Hoy día, las biopsias de la piel ya han podido determinar que existe vasculopatía trombogénica pauciinflamatoria con depósitos de complemento C5b-9 y C4d.

La explicación más viable para este fenómeno es el constatar mecanismos dependientes de vías alternas de complemento así como de lectina, y los fenómenos trombóticos en los afectados con este agente infeccioso, y de ello, suponer el camino para que se establezcan los fenómenos procoagulantes en otros órganos. ${ }^{5}$ La clasificación, propuesta por Galván Casas y colaboradores, ${ }^{6}$ indicó que las manifestaciones cutáneas de COVID-19 fuesen organizadas en cinco patrones clínicos. De éstos, el patrón número cinco corresponde al denominado "vasculonecrótico", que engloba lesiones livedoides y necróticas, y que aparece con mayor frecuencia en pacientes ancianos (edad media de 63 años) con un curso severo de la infección (mortalidad del $10 \%$ ) y un evidente síndrome de activación macrofágica. Las livedos, con patrones vasculares tipo reticularis (morfología con patrón de disposición en anillos completos) y racemosa, con ramificación más grande y anillos incompletos, son fiel reflejo de problemas intraluminales: flujo sanguíneo lento intravascular, propiciados por crioglobulinemia, criofibrinogenemia, u obstrucción de vasos por anticuerpos antifosfolípidos, necrosis por heparina y/o vasculopatía livedoide). El clínico seleccionará el sitio exacto para la toma de biopsia por escisión elíptica de piel de apariencia normal en el centro del patrón de red. Estos cambios son secundarios a la respuesta vasoespástica por depleción del flujo sanguíneo hacia y dentro de la piel, y probable "fuga" de sangre desoxigenada en el plexo venoso y subsecuente "apariencia viva".

En el escenario de este cortejo inmunológico, las células de la línea blanca evidencian a los linfocitos $\mathrm{T}$ y a los 
macrófagos en esa variante de respuesta inmune hipercitoquinética y trombótica asociada. Remata esto en una verdadera hiperexpresión "no controlada" de citoquinas en el organismo, por alteración de células específicas de esa citada línea. ${ }^{7}$ La expresión clínica tan pleomórfica hacia la piel, de estos cambios microangiopáticos, puede comprenderse de forma práctica al subdividir las reacciones en dos tipos: 1) las que se caracterizan por un fenómeno del todo similar al síndrome de activación macrofágica (isquemia acral, gangrena, púrpura retiforme, livedos racemosa y reticularis), con un pronóstico ominoso con relación a la morbimortalidad de los enfermos, y 2) aquellas que se podrían relacionar con un pronóstico benigno autorresolutivo en pacientes generalmente jóvenes, por activación de una respuesta temprana al interferón tipo I (lesiones similares a perniosis o "pseudosabañones"). ${ }^{8}$ La activación del complemento y las diversas respuestas inmunes permiten el reclutamiento de leucocitos, con una proliferación exagerada de linfocitos y con liberación masiva de citoquinas proinflamatorias (IL-1 $\beta$, IL-6, IL-8), de interferón gamma y de factor de necrosis tumoral (TNF) alfa, entre otros.

El interferón gamma en grandes cantidades estimula los macrófagos y libera ferritina; la IL-6 produce fiebre en los individuos y la hemofagocitosis podría conducir a pancitopenia. ${ }^{9}$ Simultáneamente, los macrófagos liberan el factor activador del plasminógeno, que puede ser uno de los múltiples mecanismos que explicarían los episodios trombóticos y la elevación del dímero $\mathrm{D}$, junto con otros hallazgos como el papel de la presencia de anticuerpos antifosfolípidos. En efecto, se han acumulado diversas

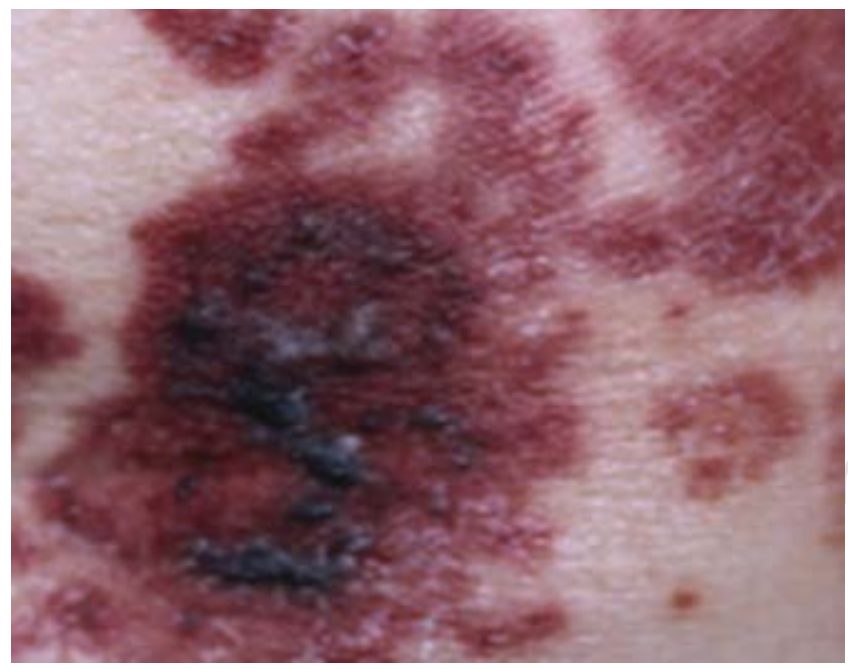

Figura 1: Iconografía que muestra un acercamiento a placas arrozariadas, violáceas y livedoides, dispuestas en forma de círculos completos, propias de la livedo reticularis.

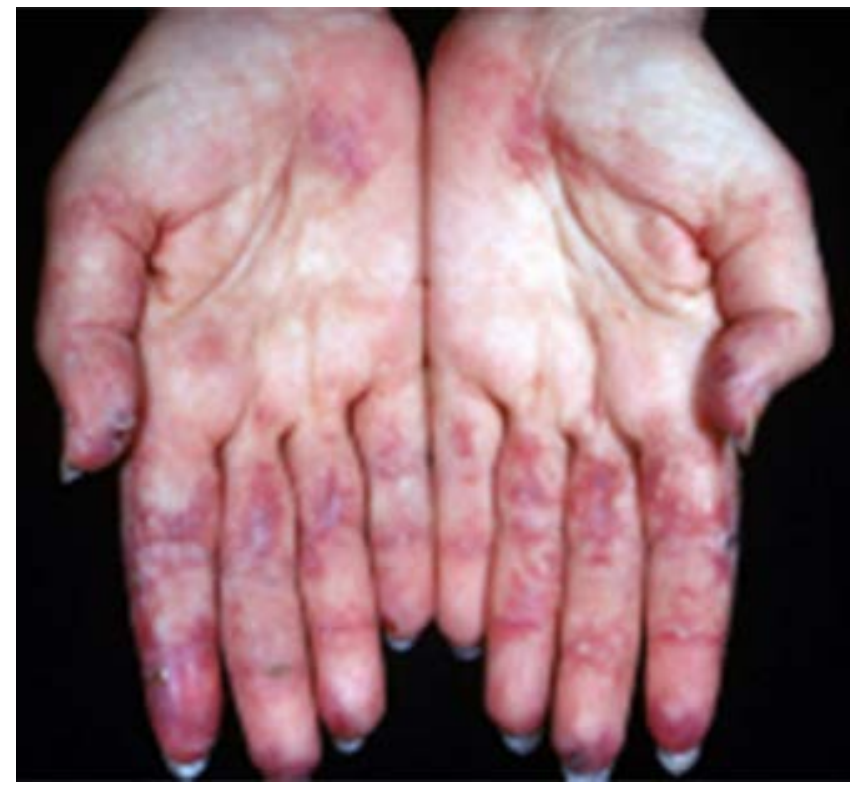

Figura 2: Ambas palmas de las manos de un enfermo con lesiones acroisquémicas activas en fase aguda.

publicaciones para determinar la presencia de anticuerpos antifosfolípidos (en particular el anticoagulante lúpico), en pacientes con contagio por el SARS-CoV-2. En esos casos, la livedo reticularis será el hallazgo más común, y con menor frecuencia: úlceras en las piernas, pseudovasculitis, gangrena digital, necrosis cutánea, hemorragias en astilla y púrpura retiforme (sugestivas de oclusión). Por laboratorio se encontrarán: anticuerpos anticardiolipina (más sensibles, más comúnmente positivos), anticoagulante lúpico y anticuerpo anti- $\beta 2$-glicoproteína I (más específico); uno o varios podrían ser positivos y falso serología positiva para sífilis. Ha sido parte sustancial que pudiese facilitar el entendimiento de los fenómenos acroisquémicos (a excepción de las lesiones tipo perniosis), de la necrosis e incluso los hallazgos de livedo reticularis y racemosa en algunos enfermos con respuestas trombóticas multisistémicas concomitantes.

Variadas observaciones han sugerido que la criofibrinogenemia pudiese estar implicada en la patogénesis de estos daños en la piel. Por lo tanto, continuará siendo relevante que ésta también deba investigarse en la presencia de infección por SARS-CoV-2, como posible mecanismo de coagulopatía y trombo en las personas afectadas. ${ }^{10,11}$ Para sospechar crioglobulinemia, pueden considerarse sangre hiperviscosa y la presencia de la "tríada de Meltzer" (púrpura, artralgia y mialgia), que en general se asocian con las crioglobulinemias de tipos II y III y diversas patologías virales o del tejido conectivo-vascular. Los pacientes que han presentado placas eritematosas localizadas en los 
dedos y/o máculas purpúricas localizadas en los pies, y cuya inmunohistoquímica muestre depósitos de C3d y $\mathrm{C} 4 \mathrm{~d}$ en las paredes de los vasos, tienen pruebas de crioproteínas positivas en dos tercios (65\%) de los evaluados. Además, esa posible asociación entre sangre e infección podría tener implicaciones terapéuticas. Aunque el anticoagulante con heparina se ha administrado para tratar la criofibrinogenemia, parece ser menos eficaz que otros, como enoxiparina. ${ }^{12}$

Otra hipótesis que explica los cambios sistémicos y epidérmicos es la llamada sepsis viral en COVID-19, la cual se plantea a partir de los múltiples hallazgos de deterioro multiorgánico en las autopsias de aquellos que mueren por síndrome de dificultad respiratoria aguda por SARS-CoV-2., Al parecer, la gran cantidad de citoquinas liberadas, en especial el TNF alfa, inducen la muerte de las células infectadas por vías dependientes de apoptosis, sumado a la aparente capacidad del germen de infectar a los linfocitos T, lo que genera la linfopenia en estos enfermos. También se afirma actualmente que hay evidencia suficiente que fundamenta el daño esencial por SARS-CoV-2, de forma directa a la célula endotelial, con posterior inflamación difusa de ésta, y ulterior apoptosis del endotelio vascular. A favor de esta teoría se encuentran la mortalidad descrita en pacientes con antecedentes de diabetes mellitus (con micro y macroangiopatías crónicas) y/o enfermedad cardiovascular crónica ocasionando lesiones acroisquémicas cutáneas (Figuras 1 a 3).

Las lesiones acroisquémicas también son resultado de un estado procoagulante microangiopático. El paciente

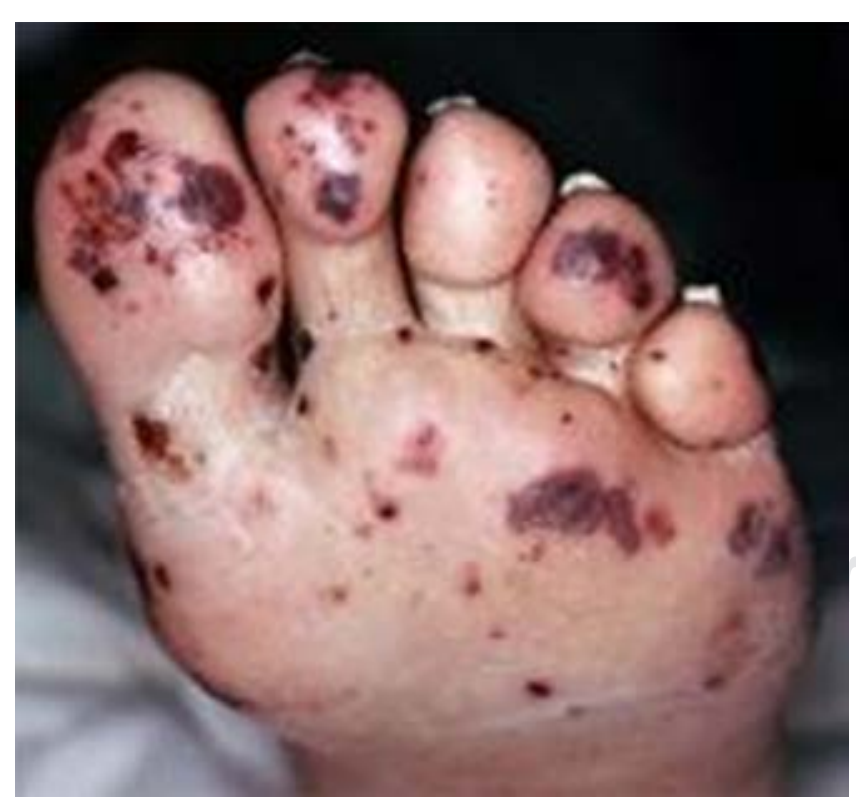

Figura 3: Cara plantar de dedos y antepié, con exantema purpúrico, sugestivo de trombosis microangiopática.

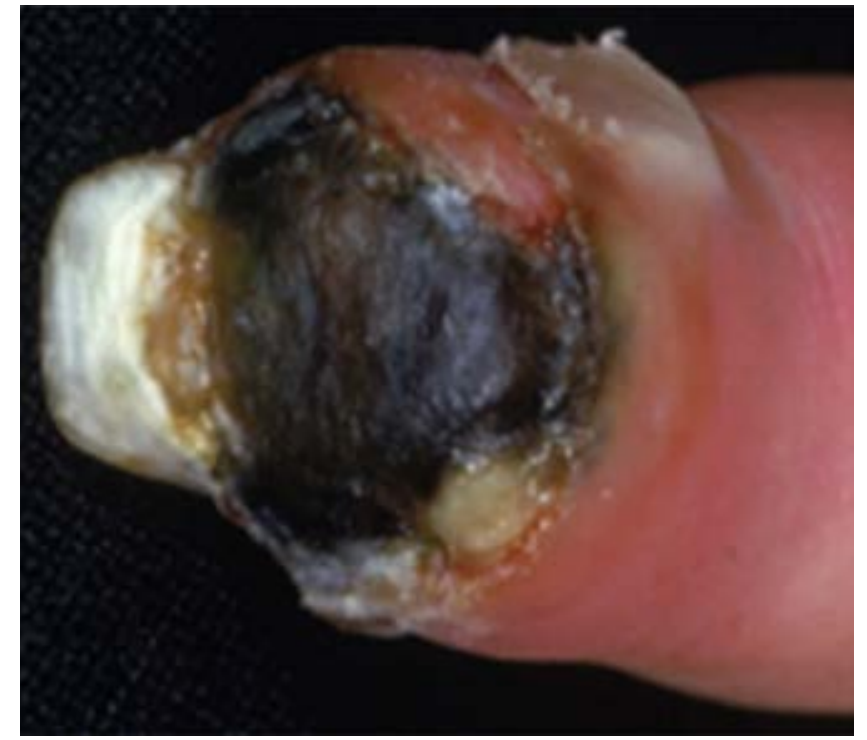

Figura 4: Dedo índice, que en su cara palmar muestra esfacelación.

con COVID-19 que desarrolle púrpura retiforme o livedo racemosa o reticularis (Figura 1), en el transcurso de su enfermedad respiratoria, deberá indagarse niveles elevados de dímero D y buscar por biopsia de piel, vasculopatía trombogénica pauci-inflamatoria con depósitos de complemento C5b-9 y C4d. ${ }^{2,6,11}$ Así parte la hipótesis de una relación entre los mecanismos dependientes de vías de complemento alterna y dependiente de lectina y fenómenos trombóticos en pacientes con infección por SARS-CoV-2, con la subsecuente explicación del porqué existen fenómenos procoagulantes en otros órganos. Tanto insuficiencia respiratoria aguda como la coagulopatía sistémica son aspectos fundamentales que propenden a una alta morbimortalidad de las personas con SARS-CoV-2. Los datos recientes muestran que casi el $20 \%$ de los pacientes con COVID-19 presentan anomalías graves de la coagulación (Figura 4). Algunos casos desarrollan síndrome multivascular catastrófico (Figuras 5 y 6). Como corolario, merece la pena enfatizar estas osbervaciones:

1. El estado protrombótico en la infección por COVID-19 está asociada con estado multidisfuncional donde intervienen: hiperreactividad macrofágica, hipofibrinólisis, hipercoagulabilidad, sistema del complemento sobreactivado y un sistema renina-angiotensina-aldosterona en desorden, debido a la disfunción endotelial.

2. Las autopsias de pulmones y piel han mostrado estragos, revelando que las lesiones son mediadas por el complemento, con estimulación generalizada tanto de las vías alternativas como de lectina. 
3. El sistema del complemento es parte del sistema inmunológico, proporcionando una defensa innata contra los microbios y las respuestas inflamatorias mediatorias. Hay un estrecho vínculo sinergista entre dicho sistema y la activación persistente del reclutamiento de leucocitos, la reanimación de células endoteliales y la coagulación.

4. El producto de degradación C3 desempeña un papel en la detección y desactivación de la patogénesis, ya que se adhiere a la superficie del SARS-CoV-2 y puede ser transportado a nivel intracelular. Los estudios recientes sugieren el concepto de inmunotrombosis, y que la fragmentación de C3 con su depósito ulterior, en las células, son el denominador común entre el daño trombótico microvascular. El uso de inhibidores de complemento se ha intentado para frenar la trombosis sistémica relacionada con COVID-19, por ejemplo eculizumab, ravulizumab y tocilizumab. ${ }^{1,4,6,11}$ La inmunotrombosis y otros tipos microangiopatías trombóticas comparten características como la microangiopatía por tal enfermedad. Es de subrayar que el uso de heparina pudiese ser peligrosa, posiblemente contribuyendo al componente hemorrágico de la microangiopatía, y mejor se recomienda no usarla. ${ }^{11,13,14}$ Con lo relatado, será ideal contar con biopsias de piel que incluyan estudio inmunohistológicos en pacientes COVID-19, donde se postule la lesión microangiopática y/o trombótica. Dichos hallazgos de inmunofluorescencia darán "luz en el camino", a fin de comprender la patogénesis de la hipercoagulopatía y la inmunotrombosis microvascular. Las características de la inmunofluorescencia podrán asimismo definir más la intervención específica. 1,3,13

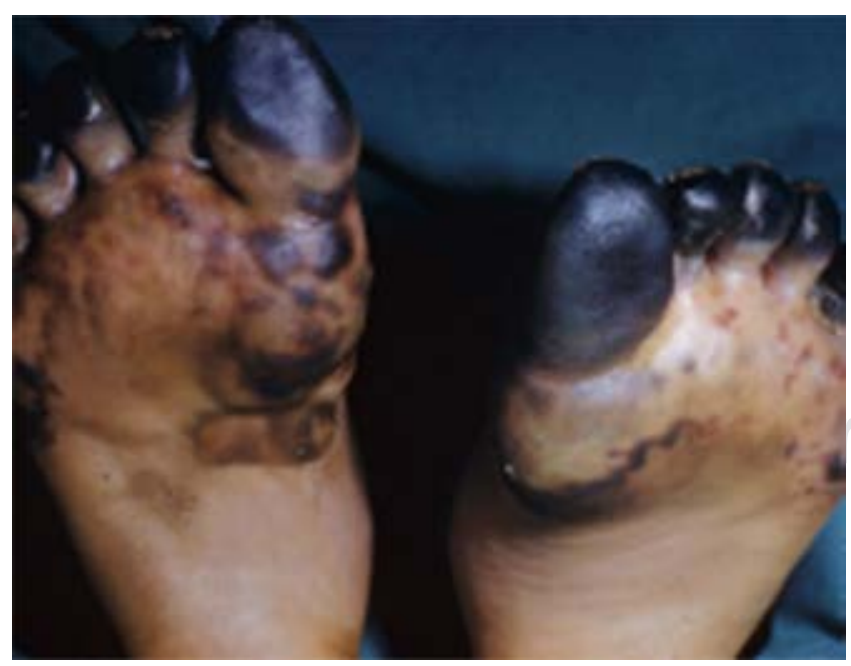

Figura 5: Todos los dedos de ambos pies con gangrena seca, secundaria a acrotrombosis por COVID-19 grave.

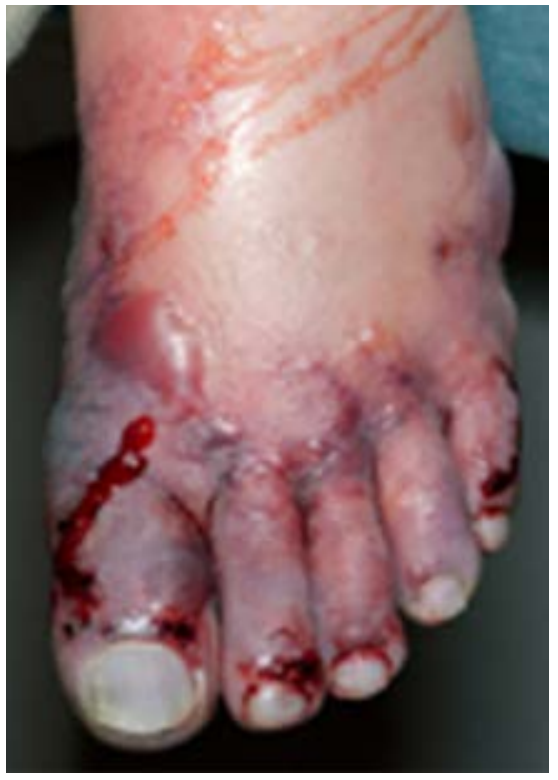

Figura 6:

Fase "agónica" bulosa acroisquémica en la totalidad de la región anterior del pie, a pocas horas de establecida.

Aún en el caso de la eliminación aparente de la pandemia en los próximos meses, las estimaciones para los periodos postpandemia prevén rebrotes ocasionales hasta 2024. No queda otra opción que estar preparados. Hay que conservarse optimistas, pero serenos. Los informes parcialmente falsos hacen daño, porque introducen datos erróneos, manipulados y tendenciosos en un contexto aparentemente bien argumentado. Por ahora, se puede aceptar que en este escenario inédito de abominable incertidumbre y desasosiego, resulta del todo difícil generar confianza hacia sistemas abstractos como ese llamado ciencia.

\section{REFERENCIAS}

1. Sanghvi AR. COVID-19: An overview for dermatologists. Int J Dermatol. 2020; 59 (12): 1437-1449.

2. Tosti G, Barisani A, Queirolo P, Pennacchioli E, Villa L, Lodeserto $\mathrm{AM}$ et al. Skin signs resembling vascular acrosyndromes during the COVID-19 outbreak in Italy. Clin Exp Dermatol. 2020; 45 (6): 757 758.

3. Mazzotta F, Troccoli T. Acute acro-ischemia in the child at the time of COVID-19. Eur J Pediat Dermatol. 2020; 30 (2): 71-74.

4. Fernandez-Nieto D, Jimenez-Cauhe J, Suarez-Valle A, MorenoArrones OM, Saceda-Corralo D, Arana-Raja A et al. Characterization of acute acral skin lesions in nonhospitalized patients: A case series of 132 patients during the COVID-19 outbreak. J Am Acad Dermatol. 2020; 83 (1): e61-e63.

5. Zhang Y, Xiao M, Zhang S, Xia P, Cao W, Jiang W et al. Coagulopathy and Antiphospholipid Antibodies in Patients with Covid-19. N Engl J Med. 2020; 382 (17): e38.

6. Galván Casas C, Catala A, Carretero Hernández G, Rodríguez-Jiménez P, Fernández-Nieto D, Rodríguez-Villa Lario A et al. Classification of the cutaneous manifestations of COVID-19: a rapid prospective nationwide consensus study in Spain with 375 cases. Br J Dermatol. 2020; 183 (1): 71-77. 
7. Lippi G, Plebani M. Laboratory abnormalities in patients with COVID-2019 infection. Clin Chem Lab Med. 2020; 58 (7): 1131-1134.

8. Gavriilaki E, Brodsky RA. Severe COVID-19 infection and thrombotic microangiopathy: success does not come easily. Br J Haematol. 2020; 189 (6): e227-e230.

9. Song WC, FitzGerald GA. COVID-19, microangiopathy, hemostatic activation, and complement. J Clin Invest. 2020; 130 (8): 3950-3953.

10. Magro C, Mulvey JJ, Berlin D, Nuovo G, Salvatore S, Harp J et al. Complement associated microvascular injury and thrombosis in the pathogenesis of severe COVID-19 infection: a report of five cases. Transl Res. 2020; 220: 1-13.

11. Romaní J, Baselga E, Mitja O, Riera-Martí N, Garbayo P, Vicente A et al. Chilblain and acral purpuric lesions in spain during Covid confinement: retrospective analysis of 12 cases. Actas Dermosifiliogr. 2020; 111 (5): 426-429.
12. Marraha F, Al Faker I, Gallouj S. A review of the dermatological manifestations of coronavirus disease 2019 (COVID-19). Dermatol Res Pract. 2020; 2020: 9360476. doi: 10.1155/2020/9360476.

13. Varga Z, Flammer AJ, Steiger $P$, Haberecker $M$, Andermatt R, Zinkernagel AS et al. Endothelial cell infection and endotheliitis in COVID-19. Lancet. 2020; 395 (10234): 1417-1418.

14. Micevic G, Morris J, Lee AI, King BA. Perniolike lesions and coagulopathy in a patient with COVID-19 infection. JAAD Case Rep. 2020; 6 (12): 1294-1296.

Conflicto de intereses: Los autores declaran no tener conflicto de intereses en esta publicación. 